\title{
Group Education for Patients with Rheumatoid Arthritis
}

\author{
Erik Taal, MA ${ }^{\mathrm{a}}$, Rob P. Riemsma, MA ${ }^{\mathrm{a}}$, Herman LM Brus, $\mathrm{MD}^{\mathrm{b}}$, \\ Erwin R. Seydel, $\mathrm{PhD}^{\mathrm{a}}$, Johannes J. Rasker, $\mathrm{MD}^{\mathrm{a}, \mathrm{b}}$ and Oene Wiegman, $\mathrm{PhD}^{\mathrm{a}}$ \\ ${ }^{a}$ Department of Psychology, University of Twente, P.O.B. 217, 7500 AE Enschede, ${ }^{b}$ Department of Rheumatology, Medisch Spectrum \\ Twente, P.O.B. 50000, $7500 \mathrm{KA}$ Enschede (Netherlands)
}

\begin{abstract}
Patients with rheumatoid arthritis must learn to adjust their exercise, rest and medication to the varying activity of the disease. Patient education can help patients in making the right decisions about adjustments in their treatment regimen and in attaining "self-management" behaviors. We developed a group education program based on social learning theory and the 'Arthritis SelfManagement Course' developed in the USA by Lorig. Goal of the program is the strengthening of self-efficacy, outcome expectations and selfmanagement behaviors of RA patients which may lead to better health status. The program has been evaluated in an experimental design. We established significant positive effects of the group training on functional disability, joint tenderness, practice of relaxation and physical exercises, self-management behavior, outcome expectations, self-efficacy function and knowledge. After 14 months we still found effects on practice of physical exercises, selfefficacy function and knowledge.
\end{abstract}

Key words: Rheumatoid arthritis; Patient education; Self-management; Self-efficacy.

\section{Introduction}

Rheumatoid arthritis (RA) is a chronic, disabling disease characterized by an unpredictable course with periods of exacerbation and remission of disease activity (Rasker and Cosh, 1987; Schumacher, 1988).
Since RA cannot be cured, the goals of treatment and management are the relief of pain, the prevention of joint destruction, and the preservation or improvement of the patient's functioning. Treatment is usually a combination of rest, exercise and medication (Ruddy, 1985). This regime must constantly be adjusted to the changing disease activity. This requires adequate treatment and support by health professionals. The patient himself also has an important role in the management of the disease. He has to learn to adjust rest, exercise and medication to the, sometimes even daily, varying disease activity. Patient education can help patients in making the right decisions about adjustments in their treatment regime and in attaining the necessary "self-management" behaviors (Lorig et al., 1987). Eventually this may lead to better health status, i.e. reduced pain and reduced functional disabilities (Bradley et al., 1984; Lorig et al., 1987; Mullen et al., 1987). Lorig et al. (1987) reviewed the arthritis patient education and concluded that the most successful educational programs (i.e. those affecting health status and behavior) emphasize the development of a daily routine of selfmanagement activities and pay attention to physical exercise, coping, self-efficacy and problem-solving. They stated also that forthcoming studies should focus on mechanisms by which effects are achieved. 
According to social learning theory the most important mechanisms in changing behavior are self-efficacy and outcome expectations (Bandura, 1986). Outcome expectation refers to a person's estimate that recommended behavior will have a beneficial effect. Selfefficacy expectation refers to beliefs in one's capabilities to execute successfully the behavior required to produce a certain desired outcome. Especially self-efficacy is an important determinant of self-management behavior. Self-management involves a constant process of making behavioral choices and decisions. Self-efficacy expectations strongly influence these choices and decisions, determine the amount of effort made, and the persistence of the effort in performing self-management activities (Bandura, 1986). Interventions to enhance self-management behavior should be aimed at strengthening self-efficacy expectations.

In relation to RA self-efficacy expectations seem to be of major importance. The unpredictable course and varying disease activity of RA may cause patients to view their disease as uncontrollable resulting in decreased selfefficacy expectations about the "selfmanagement" of the consequences of the disease (Bradley et al., 1984). The feeling they cannot control their disease may cause patients to experience anxiety and depression. This, in turn, can lead to increased perceptions of pain, and reduced efforts to cope with the consequences of the disease or to engage in daily activities. As a consequence health status may further deteriorate. Studies have shown that there are associations between self-efficacy expectations and health status (e.g. pain, depression, functional disability) in arthritis patients, and that changes in selfefficacy are related to changes in health status (Lorig et al., 1989; O'Leary et al., 1988; Shoor and Holman, 1984; Taal et al., this issue). From these studies no conclusions can be drawn about a causal relationship between self-efficacy expectations and health status. One may expect that the causality goes both ways. According to Bandura (1986) strengthening of self-efficacy expectations will lead to improvements in health status, but it is also clear that health status affects selfefficacy expectations.

The most effective methods to influence self-efficacy expectations are methods based on performance accomplishments and modeling. Performance accomplishments are the most influential source of efficacy information because they are based on personal mastery experiences. One of the best ways to strengthen self-efficacy expectations and to master new skills is to have patients set goals for themselves for a specific activity, and to write these goals in the form of a contract with oneself. Goals should be realistic and attainable. It is very important to provide patients with feedback about their performance. Especially the combination of goal setting (in contracts) and feedback has shown to be effective in strengthening self-efficacy and mastering skills (Bandura, 1986; Gonzalez et al., 1990). Modeling can be done by patients who are successful in coping with certain problems and who act as models for other patients. In group education modeling can be used very effectively by group members helping each other in solving problems (Gonzalez et al., 1990). Every time a problem is stated, the leader should ask the other group members if one of them ever had a similar problem or has any ideas about how to solve the problem. This strategy teaches group members that they really are experts and have useful knowledge to share. Furthermore, it shows them they do not always have to rely on professionals for advice and this approach may generate new solutions not thought of by health professionals.

In the USA the "Arthritis SelfManagement Course" (ASMC) has been developed, a group education program for people with arthritis (Lorig et al., 1985). Assumptions underlying the ASMC are that enhanced knowledge and practice of selfmanagement behaviors will lead to improved physical function and less pain. Program con- 
tent includes the teaching of information about the nature of arthritis, medication and treatment, practice of physical and relaxation excrcises, problem-solving and communication skills. Effective methods are used to master self-management skills and to strengthen self-efficacy expectations like guided practice of exercises, goal setting in contracts and the provision of feedback about accomplishments. The ASMC has shown to be successful and leads to increased knowledge, performance of taught behaviors, and less pain (Lorig et al., 1985; Lorig et al., 1989).

Based on the experiences in the USA with the ASMC, social learning theory, and a pilot study on RA patients and health professionals we developed an educational group program (Taal et al., this issue; Taal, Seydel, Cliteur, Rasker and Wiegman, 1991a, 1991b). Goal of the program is to strengthen self-efficacy and outcome expectations and self-management behaviors regarding pain, functional abilities, and other physical and psychosocial consequences of RA which, eventually, can lead to better health status. Our program differs in some aspects from the ASMC. In the ASMC people with various rheumatic diseases participate; our program is specifically aimed at RA patients. Most health professionals that were interviewed in our pilot study stated that groups should be led by professionals (Taal et al., 1991b). Furthermore most of them meant that RA patients should have an individualized program of physical exercises tuned to their personal circumstances. Based on these results from our pilot study we decided that groups should not be led by lay-persons, as in the ASMC, but by professionals. We also decided to have patients guided individually by a physiotherapist, besides to the group program. This physiotherapist can design an individual program of physical exercises for each patient. During group sessions no physical exercises are practised, but problems patients have with their exercise program may be discussed. In the ASMC physical exercises are practised during group sessions, and patients are not individually guided by a physiotherapist.

Here we report the effects of participation by RA patients in the group education program on health status, behavior, self-efficacy and outcome expectations and the knowledge about rheumatoid arthritis.

\section{Methods}

\section{The group program}

The program consists of five weekly $2-\mathrm{h}$ group sessions with six to eight patients, if preferred with their partners. Each group has two leaders who have expertise on rheumatic diseases and/or on leading groups. In this study the groups were for example led by nurses specialized in rheumatic diseases, physiotherapists or social workers. Furthermore the leaders received two days of training and a teaching manual (Taal et al., 1991a). Patients receive a programbook with information on the sessions, a self-help guide, various brochures on RA and an audiotape with relaxation exercises (Taal et al., 1991b,1991c).

The program includes the following components:

Contracting, goal setting and feedback. Contracts and goal setting are systematically used to stimulate the practising of excrcises at home. At the end of every session patients state their goal for the next week in a written contract. At the beginning of every next session feedback is given. Results of and problems with contracts are discussed. Patients are encouraged to solve problems themselves.

Self-management and problem-solving. Participants are explained that self-management often means solving of problems one has due to the disease, like pain or functional impairments. Problem-solving techniques are exercised. Patients get home-work instructions on problem-solving.

Information on $R A$ and treatment. Minimal facts are taught during sessions, but sources are mentioned for further information and written materials on RA are handed out. $\mathrm{Pa}$ - 
tients are explained how to read this information, and for example guidelines are given to evaluate different methods of treatment, including complementary medicine.

Pain management and relaxation. Information is given about the relationships between pain, muscle tension, stress and depression and cognitive methods of pain management. Extensive information is given on relaxation as a method of pain management. During every session relaxation exercises are practised and patients are advised to perform these exercises at home using an audiotape. During the first four sessions exercises are practised based on Jacobson's progressive relaxation (Jacobson, 1938). With this method muscles are alternately tightened and relaxed, thus one learns how it feels to be relaxed and to be tense, and how one can induce relaxation. In Session 5 this exercise is extended with "guided imagery", a kind of daydream where patients are asked to imagine that they are in a beautiful flower garden.

Physical exercises. Information is given on exercises and patients are stimulated to exercise at home. All patients are referred to a physiotherapist for individual instructions and guidance.

Communication skills. Using a role-play patients are given insight in communication processes. Furthermore problems in doctorpatient communication are discussed.

Coping with depression. Methods are discussed to cope with depression. It is emphasized to maintain social contacts and daily activities.

\section{Design}

The program has been evaluated in a fieldexperimental design with an experimental group and a control group. Assessments of both groups were performed at baseline 1 week prior to the start of the intervention, after 6 weeks (one week after intervention), 4 months and 14 months after baseline. Patients in the experimental group participated in the group program and were at the start of the in- tervention referred to a physiotherapist for individual guidance. Patients in the control group were also referred to a physiotherapist but did not participate in the group program and did not receive instruction books and other materials.

\section{Patients}

With the use of a nationwide Standard Diagnosis Registration system, 140 RA patients, who entered the practices of three rheumatologists less than eight years ago, were selected to participate in the study (Janssens, 1987). Selection criteria were a diagnosis of RA according to the revised ARA criteria (Arnett et al., 1988), age between 21 and 65, and a maximum use of eight years of second-line medication. This last criterium was set to get a homogeneous group of patients with a relatively good health status because of the strong emphasis in the program on physical an endurance exercises. Seventyfive patients agreed to participate. These patients were randomly assigned to the experimental or control group. Thirty-eight patients were assigned to the experimental group and 37 patients to the control group. Between selection and 14 month assessment 13 patients have dropped out. At baseline these drop-outs had less social contacts and were more anxious than patients who completed the study "Social activities": 5.40 vs. $3.98, t=2.36, P<$ 0.05 ; "Anxiety": 5.30 vs. $3.40, t=2.53, P<$ 0.05 ). There were no other significant differences.

Five patients in the experimental group who were still in the study at 14 months are excluded from analyses because they did not attend all five group sessions.

\section{Assessments}

At baseline, after 4 months and after 14 months all patients were clinically assessed by a physician (HLMB): joint tenderness score as described by Ritchie et al. (1968). Blood samples were taken for measurement of Erythrocyte Sedimentation Rate (ESR), Hemoglobin concentration $(\mathrm{Hb})$ and Thrombocytes number (higher ESR and Thrombocytes number 
and lower $\mathrm{Hb}$ concentration are indications of increased disease activity).

With mailed questionnaires at baseline, after 6 weeks, 4 months and 14 months health status, behavior, outcome and self-efficacy expectations and knowledge were assessed.

To measure Health Status the scales Mobility (Cronbach's $\alpha=0.22$ ), Physical Activities $(\alpha=0.68)$, Dexterity $(\alpha=0.73)$, Household Activities $(\alpha=0.60)$, Activities of Daily Living $(\alpha=0.46)$, Pain $(\alpha=0.84)$, Anxiety $(\alpha=0.93)$, Depression $(\alpha=0.85)$, Social Activities $(\alpha=0.83)$ and Arthritis Impact (a visual analog scale for global assessment of the effect of arthritis on well-being) of The DUTCH-AIMS were used (Taal et al., 1989). Scores on DUTCH-AIMS scales may range from 0 (very good status) to 10 (very bad status). Because of the low internal consistencies (Cronbach's $\alpha$ ) at baseline, in this population of RA patients with a relatively good health status, the scales Mobility and Activities of Daily Living are excluded from the effect analyses.

To measure functional disability not only the specific scales Physical Activities, Dexterity and Household Activities from the DUTCH-AIMS were used but also a Dutch version of the M-HAQ (eight items, $\alpha=0.83$ ), a more general measure of functional disability (Pincus et al., 1989). Scores may range from 1 (without any difficulty) to 4 (unable to do).

The performance of exercises were measured by the reported frequency (times/week) of relaxation, physical and endurance exercises (walking/swimming/bicycling). Selfmanagement activities were measured with seven items to be answered on five pointscales ranging from never (1) to always (5) $(\alpha=0.48)$.

Outcome expectations were measured by a seven-item scale $(\alpha=0.66)$. Items could be answered on five-point scales ranging from totally disagree (1) to totally agree (5).

Self-efficacy expectations regarding the performance of relaxation, physical and en- durance exercises were each measured with one question. Self-efficacy expectations regarding self-management activities were measured by a seven-item scale $(\alpha=0.70)$. Items could be answered on five-point scales ranging from totally disagree (1) to totally agree (5). Furthermore a Dutch version of an American instrument to measure arthritis sclfefficacy developed by Lorig et al. (1989) was used. This instrument contains the scales SelfEfficacy Pain (five items related to coping with pain, $\alpha=0.76$ ), Self-Efficacy Function (eight items related to physical function, $\alpha=0.88$ ) and Self-Efficacy Other Symptoms (eight items related to coping with other symptoms like depression, fatigue, frustrations, $\alpha=0.77$ ). Items could be answered on five-point scales ranging from totally disagree (1) to totally agree (5).

Knowledge about RA and its treatment and management was assessed with a 13 item true/false scale $(\alpha=0.80)$.

\section{Results}

Table 1 shows some characteristics of patients in the study at 14 months. There were no significant differences between experimental and control group regarding sex, age, disease duration, functional class as assessed by a physician, and rheumatoid factor.

Table 2 shows mean values at baseline and change scores between baseline and 6 weeks, 4 months and 14 months for patients in the control group and patients in the experimental group. Tested with $t$-test we found significant differences at baseline between experimental and control group for joint tenderness assessed by physician $(t=2.57, P$ $<0.02)$ and self-efficacy pain $(t=2.53, P<$ 0.02 ). Changes between baseline and post measurements were analyzed with univariate analyses of covariance on mean scores for each dependent variable at post-measurements with baseline scores of dependent variable and baseline scores of joint tenderness and self-efficacy pain as covariates. 
Table 1. Characteristics of the patients in the study at 14 months.

\begin{tabular}{lll}
\hline & $\begin{array}{l}\text { Control } \\
\text { group } \\
(n=30)\end{array}$ & $\begin{array}{l}\text { Expcrimental } \\
\text { group } \\
(n=27)\end{array}$ \\
\hline Sex & 8 & 7 \\
$\quad$ Male & 22 & 20 \\
$\quad$ Female & & \\
Age & & \\
$\quad$ Mean (years) & 49.5 & 49.7 \\
$\quad$ Range & $24-64$ & $27-64$ \\
$\begin{array}{l}\text { Disease duration } \\
\quad \text { Years }\end{array}$ & 4.7 & 3.9 \\
$\quad$ Range & $1-29$ & $1-20$ \\
Functional classification & & \\
$\quad$ I & 8 & 5 \\
$\quad$ II & 21 & 20 \\
$\quad$ III & 1 & 2 \\
Rheumatoid factor & & \\
$\quad$ Seronegative & 19 & 10 \\
$\quad$ Seropositive & 11 & 17 \\
\end{tabular}

There are no significant differences between control and experimental group.

${ }^{\mathrm{a}} \mathrm{I}$, No restriction of ability to perform normal activities; II, Moderate restriction but adequate for normal activities; III, Marked restriction, inability to perform most duties of the patient's usual occupation or self-care.

Before applying analysis of covariance we tested on the assumptions of homogeneity of variance and homogeneity of regression or parallelism. For variables that did not satisfy these criteria we calculated change scores between baseline and post-measurement(s). Differences in change scores between experimental and control group for these variables were tested with the nonparametric MannWhitney $U$-test.

Directly after intervention (6 weeks) we detected significant beneficial effects of the group education, compared to the control condition, on functional disability measured with M-HAQ $\left(F_{1,50}=5.37, P<0.03\right)$, the performance of relaxation exercises $(U=$ 193.5, $P<0.03)$, physical exercises $(U=$ 168.0, $P<0.006)$ and self-management activities $\left(F_{1,47}=8.73, P<0.006\right)$, outcome expectations $\left(F_{1,49}=12.97, \quad P<0.002\right)$, self-efficacy function $\left(F_{1,51}=4.80, P<0.04\right)$ and knowledge $(U=96.5, P<0.0001)$. For anxiety we found a tendency in the expected direction $(U=291.0, P<0.09)$.

After 4 months we still found significant positive effects on functional disability measured with M-HAQ $\left(F_{1,50}=5.67, P<\right.$ $0.03)$, joint tenderness $(U=265.0, P<0.02)$ which, however, was not assessed directly after intervention, performance of physical exercises $(U=185.0, P<0.02)$ and knowledge $(U=116.5, P<0.0001)$.

After 14 months there were significant positive long term effects of group education on performance of physical exercises $(U=161, P$ $<0.004)$, self-efficacy function $\left(F_{1,51}=4.36\right.$, $P<0.05)$ and knowledge $(U=138.5, P<$ 0.0003 ). For joint tenderness there was a tendency in the expected direction after 14 months $(U=318.0, P<0.09)$.

\section{Discussion}

In this study we have evaluated a group education program for patients with RA. Goal of the group education program was to strengthen self-efficacy and self-management behavior regarding pain, functional abilities, and other physical and psychosocial consequences of RA which may lead to better health status. Part of this goal is achieved with the program.

Effects of the program were evaluated with clinical assessment by a physician, blood measures and self-report measures. Most selfreport measures showed good internal consistency (Cronbach's $\alpha$ ). Only the scale to measure self management activities had low internal consistency $(\alpha=0.48)$.

We found beneficial effects of education on knowledge, outcome expectations, self- 
Table 2. Mean scores at baseline and change scores between baseline and 6 weeks, 4 months and 14 months for health status, laboratory tests, behavior, self-efficacy, outcome expectations and knowledge in the control group $(n=30)$ and the experimental group $(n=27)$.

\begin{tabular}{|c|c|c|c|c|c|c|c|c|}
\hline & \multicolumn{2}{|c|}{ Baseline scores } & \multicolumn{2}{|c|}{ Six weeks change } & \multicolumn{2}{|c|}{ Four months } & \multicolumn{2}{|c|}{ Fourteen months } \\
\hline & Control & $\begin{array}{l}\text { Experi- } \\
\text { mental }\end{array}$ & Control & $\begin{array}{l}\text { Experi- } \\
\text { mental }\end{array}$ & Change & $\begin{array}{l}\text { Experi- } \\
\text { mental }\end{array}$ & Change & $\begin{array}{l}\text { Experi- } \\
\text { mental }\end{array}$ \\
\hline \multicolumn{9}{|l|}{ Health Status } \\
\hline Physical activities & 4.24 & 4.64 & -0.56 & 0.08 & -0.56 & -0.64 & -0.48 & -0.16 \\
\hline Dexterity & 2.88 & 3.08 & 0.08 & 0.00 & 0.32 & -0.41 & 0.00 & -0.16 \\
\hline Household Activities ${ }^{a}$ & 0.62 & 0.74 & -0.15 & 0.18 & -0.12 & 0.00 & -0.26 & 0.00 \\
\hline Pain & 4.52 & 4.75 & -0.14 & -0.50 & -0.67 & -0.54 & -0.33 & -0.02 \\
\hline Depression & 2.43 & 2.33 & -0.50 & -0.58 & -0.66 & -0.50 & -0.60 & -0.25 \\
\hline 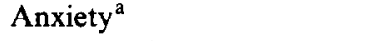 & 3.37 & 3.27 & -0.26 & -0.68 & -0.31 & -0.36 & -0.26 & -0.54 \\
\hline Social Activities & 4.26 & 3.52 & -0.36 & 0.13 & -0.31 & 0.02 & -0.47 & -0.06 \\
\hline Arthritis Impact & 4.18 & 4.50 & -0.12 & -0.16 & -0.50 & -0.30 & -0.25 & -0.47 \\
\hline Disability (M-HAQ) & 1.26 & 1.39 & 0.16 & $-0.01^{*}$ & 0.09 & $-0.03^{*}$ & 0.15 & 0.09 \\
\hline $\begin{array}{l}\text { Joint tenderness }{ }^{\text {a }} \\
\text { Laboratory Tests }\end{array}$ & 4.10 & $7.56^{*}$ & NA & NA & -1.77 & $-4.67^{*}$ & 1.63 & 0.77 \\
\hline ESR $^{a}$ & 17.15 & 20.69 & NA & NA & -3.73 & 0.27 & 9.50 & 3.58 \\
\hline Hemoglobin $^{\mathrm{a}}$ & 8.40 & 8.38 & NA & NA & -0.10 & -0.10 & -0.01 & -0.16 \\
\hline \multicolumn{9}{|l|}{ Behavior } \\
\hline Relaxation $^{\mathrm{a}}$ & 3.04 & 2.35 & 0.28 & $2.52^{*}$ & -0.64 & 0.78 & 0.00 & 0.74 \\
\hline Physical exercises $^{\text {a }}$ & 3.60 & 2.00 & -0.80 & $2.65^{* *}$ & -1.36 & $2.17^{*}$ & -2.12 & $1.91 * *$ \\
\hline Endurance exercises & 8.05 & 7.65 & 0.50 & 0.29 & 2.72 & 0.00 & 0.27 & 0.59 \\
\hline Self-management activities & 3.62 & 3.63 & -0.07 & $0.35^{* *}$ & 0.08 & 0.22 & 0.07 & 0.23 \\
\hline $\begin{array}{l}\text { Outcome Expectations } \\
\text { Self-efficacy }\end{array}$ & 4.31 & 4.06 & -0.01 & $0.36^{* *}$ & 0.05 & 0.26 & 0.08 & 0.20 \\
\hline Relaxation & 4.30 & 4.39 & 0.10 & -0.12 & 0.17 & -0.16 & -0.39 & 0.03 \\
\hline Physical exercises $^{\mathrm{a}}$ & 4.45 & 4.19 & 0.07 & 0.08 & 0.00 & 0.23 & -0.04 & -0.04 \\
\hline Endurance exercises & 3.72 & 3.96 & 0.49 & 0.19 & 0.56 & 0.08 & 0.49 & 0.19 \\
\hline Self-management activities ${ }^{a}$ & 4.20 & 4.16 & 0.08 & 0.11 & 0.09 & 0.07 & 0.16 & -0.03 \\
\hline SE-pain & 3.68 & $3.09^{*}$ & 0.11 & 0.43 & 0.24 & 0.40 & 0.15 & 0.33 \\
\hline SE-function & 4.33 & 4.03 & -0.13 & $0.17^{*}$ & -0.02 & 0.07 & -0.06 & $0.17^{*}$ \\
\hline SE-other symptoms ${ }^{a}$ & 3.95 & 3.70 & 0.03 & 0.11 & 0.14 & 0.08 & 0.11 & 0.10 \\
\hline Arthritis knowledge $^{\text {a }}$ & 7.36 & 7.17 & 0.14 & $3.18 \dagger$ & -0.07 & $2.35 \dagger$ & -0.11 & $2.48 \dagger$ \\
\hline
\end{tabular}

${ }^{*} P<0.05 .{ }^{* *} P<0.01 . \dagger P<0.001$. NA, not assessed.

Differences at baseline between control and experimental group tested with $t$-test. Differences in mean scores at 6 weeks, 4 months and 14 months between control and experimental group tested with univariate analysis of covariance with baseline scores of dependent variable, Ritchie-index and self-efficacy pain as covariates.

${ }^{a} \mathrm{C}$ hanges between baseline and 6 weeks, 4 months and 14 months tested with Mann-Whitney $U$-test.

efficacy function, the performance of relaxation exercises, physical exercises and selfmanagement activities. If we look at the data for the performance of relaxation and physi- cal exercises we see in the experimental group an increase of more than $100 \%$ one week after intervention compared to baseline in the reported weekly exercise frequency for both 
types of exercise (for relaxation from 2.35 times to 4.87 times, and for physical exercise from two times to 4.65 times) while in the control group there was only an increase of about $10 \%$ for the performance of relaxation exercises and a small decrease for physical exercises.

Regarding the various physical, social and psychological aspects of health status we established significant beneficial effects on functional disability measured with M-HAQ directly after intervention $(P<0.03)$ and after 4 months $(P<0.03)$, and on joint tenderness after 4 months $(P<0.02)$. No significant effects are found on pain, disease activity and psychological and social aspects of health status.

Assumption of our theoretical model is that changes in behavior are caused by changes in outcome and self-efficacy expectations. Regarding outcome expectations our data seem to support this assumption directly after intervention but not after 4 and 14 months. With respect to self-efficacy we found a beneficial effect on self-efficacy function, but no effects on the other self-efficacy expectations. At baseline the patients in this study already had high self-efficacy expectations regarding the behaviors that have changed between baseline and 6 weeks. Scores at baseline for self-efficacy expectations regarding the performance of relaxation exercises, physical exercises and self-management activities were all above 4 on a scale from 1 to 5 . So, strengthening of these expectations was hardly possible. Regarding endurance exercises we didn't find any educational effects. The selfefficacy expectations regarding the performance of endurance exercises were at baseline much weaker then the self-efficacy expectations regarding the other behaviors that have changed. This means that the group education only had beneficial effects on those behaviors for which patients already had high selfefficacy expectations prior to the intervention.

It was expected that the training course would lead to a better health status. This am- bitious goal has partially been achieved. We find some positive effects on functional disability and joint tenderness. In evaluating effects on health status one must take into account that patient education is given in addition to standard medical care. So, effects of patient education are always supplementary to the benefits of medication and other standard medical care. Furthermore, when we look at the baseline health status scores we see that the patients seem to have a relatively good psychological health status (depression, anxiety). In another study we established that many RA patients do not have substantial problems with depression (Taal et al., this issue). A problem in many studies that have found elevated depression scores is that the scales used to measure depression contain items about somatic symptoms that can result from depression as well as from RA (Pincus and Callahan, this issue). However, it is clear that depression might be a problem in some RA patients (Anderson et al., 1985; Blalock et al., 1989; Peck et al., 1989; Pincus and Callahan, this issue). Also regarding social activities patients seem to have minor problems. In an earlier study we also found $R A$ patients to have little problems in social activities (Taal et al., 1989; Taal et al., this issue).

Although we found behavioral changes, these changes did not lead to substantial changes in health status. Lorig et al. (1987) also concluded that often no clear relationships are found between behavioral changes and changes in health status. But there are indications that beneficial changes in health status are influenced by the strengthening of self-efficacy expectations (Lorig et al., 1989; O'Leary et al., 1988). The finding of positive effects on self-efficacy function and on functional disability in this study also support this conclusion. The fact that we did not establish changes in self-efficacy regarding pain and other symptoms might explain why we did not find substantial effects on other aspects of health status.

After 14 months we still found strong effects on knowledge and the practice of physi- 
cal exercises, and a small effect on self-efficacy function. As stated in the introduction one of the most effective methods to master new skills is the setting of goals in combination with feedback about the accomplishments. After finishing the program the patients did no longer receive feedback from the group leaders and fellow group members. So, when implementing the group program it seems advisable to hold one or more booster-sessions or to introduce other forms of feedback after the end of the training sessions in order to maintain changes due to the group education.

Our program is partly based on the American ASMC developed by Lorig et al. (1985; 1989). They also found significant effects on behavior and knowledge. Regarding health status they found different effects. Contrary to our findings they did find significant effects on pain and depression. They did not find significant effects on self-efficacy function and functional disability while we found some significant effects. There are some important differences between our study and the studies of Lorig et al. In our study only RA patients participated. In the study of Lorig et al. not only RA patients but also patients with other forms of arthritis participated. Most patients in their study were patients with osteoarthritis. Our selection of patients was also quite different. We selected patients from the files of rheumatologists while Lorig et al. recruited most of their patients through public service announcements in the mass media, so one might assume that the patients in their studies were all very motivated to participate while in our study patients joined the study because they were invited to participate by their rheumatologist. In the ASMC groups were led by lay-leaders while in our study groups were led by professionals. This may not explain the difference because in another study Lorig et al. (1986) showed that results of courses given by lay-leaders did not differ from courses led by professionals; the only differences being that professional-taught groups demonstrated greater knowledge gain while lay-taught groups had greater changes in practice of relaxation exercises.

Contrary to Lorig we did not find significant effects on pain. Regarding pain management, our program is about the same as the ASMC. Most important difference is that in our program only relaxation exercises based on progressive relaxation and guided imagery are practised, while in the ASMC also breathing exercises and Benson relaxation exercises were included (Benson and Klipper, 1987).

The fact that we found some significant effects related to function (self-efficacy function, disability), while Lorig did not, could possibly be explained by the individual instruction and guidance the patients in our program received from a physiotherapist. In our study as well as in the studies of Lorig et al. positive effects of group education were found on exercise frequency. We don't know how patients perform their exercises. Without individual guidance by a physiotherapist it is not inconceivable that exercises are not performed totally correct. This being said we must make notice of the fact that only individual guidance by a physiotherapist without group education, as was the case in our control group, did not lead to increased exercising. Our study showed that it is the combination of individual guidance by a physiotherapist with group education that is the most effective. From the literature it is known that compliance with physical exercise in RA patients, as well as in patients with other diseases, is generally quite low (Anderson et al., 1985; Sluys and Knibbe, 1991). According to Sluijs and Knibbe (1991) it is very important that exercises are imbedded in daily routines and that feedback is provided. Our program satisfies these points through the use of contracts and the providing of feedback.

\section{Acknowledgements}

This study was supported by a grant from the Dutch Prevention Foundation (Praeventiefonds). We would like to thank all the patients who participated in this study and we 
gratefully acknowledge the help and advice in this study of Dr J.W.G. Jacobs, rheumatologist (Department of Rheumatology, Academisch Ziekenhuis Utrecht), M. Rommelse, M.Sc. (Cross Association Twente), and the rheumatologists Dr J.J.M. Festen, Dr M.W.M. Kruijsen (Medisch Spectrum Twente, Enschede) and J.C.M. Oostveen, M.Sc. (Ziekenhuis Twenteborg, Almelo).

\section{References}

Anderson, K.O., Bradley, L.A., Young, L.D., McDaniel, L.K. and Wise, C.M. (1985). Rheumatoid Arthritis: review of psychological factors related to etiology, effects, and treatment. Psychological Bulletin, 98, 358-387.

Arnett, F.C., Edworthy, S.M., Bloch, D.A., McShane, D.J., Fries, J.F., Cooper, N.S. et al. (1988). The American Rheumatism Association 1987 revised criteria for the classification of rheumatoid arthritis. Arthritis and Rheumatism, 31, 315-324.

Bandura, A. (1986). Social foundations of thought and action: $A$ social cognitive theory. Englewood: Prentice-Hall.

Benson, H. and Klipper, M. (1987). The Relaxation Response. New York: Avon.

Blalock, S.J., DeVellis, R.F., Brown, G.K., Wallston, K.A (1989). Validity of the center for epidemiological studies depression scale in arthritis populations. Arthritis and Rheumatism, 32, 991-997.

Bradley, L.A., Young, L.D., Anderson, K.O., McDanicl, L.K., Turner, R.A. and Agudelo, C.A. (1984). Psychological approaches to the management of arthritis pain. Social Science and Medicine, 19, 1353-1360.

Gonzalez, V.M., Goeppinger, J. and Lorig, K. (1990). Four psychosocial theories and their application to patient education and clinical practice. Arthritis Care and Research, 3, 132-143.

Jacobson, E. (1938). Progressive Relaxation. Chicago: University of Chicago Press.

Janssens, M. (1987). Landelijke Coördinatie Reumaresearch. De Standaard Diagnose Registratie van Reumatische Ziekten en Standaardisatie van de Reumaserologie. [National coordination of research on the rheumatic diseases. The standard diagnosis register of the rheumatic diseases and standardization of rheumatic serology]. Rotterdam: Erasmus Universiteit.

Lorig, K., Chastain, R., Ung, E., Shoor, S. and Holman, H.R. (1989). Development and evaluation of a scale to measure perceived self-efficacy in people with arthritis. Arthritis and Rheumatism, 32, 37-44.

Lorig, K., Feigenbaum, P., Regan, C., Ung, E., Chastain, R.L. and Holman, H.R. (1986). A comparison of lay-taught and professional-taught arthritis self-management courses. The Journal of Rheumatology, 13, 763-767.
Lorig, K., Konkol, L. and Gonzalez, V. (1987). Arthritis patient education: A review of the literature. Patient Education and Counseling, 10, 207-252.

Lorig, K., Lubeck, D., Kraines, R.G., Seleznick, M. and Holman, H.R. (1985). Outcomes of self-help education for patients with arthritis. Arthritis and Rheumatism, 28, 680-685.

Mullen, P.D., Laville, E.A., Biddle, A.K. and Lorig, K. (1987). Efficacy of psychoeducational interventions on pain, depression and disability in people with arthritis: a meta-analysis. Journal of Rheumatology, 14, 33-39.

O'Leary, A., Shoor, S., I orig, K and Holman, H.R. (1988). A cognitive behavioral treatment for rheumatoid arthritis. Health Psychology, 7, 527-544.

Peck, J.R., Smith, T.W., Ward, J.R. and Milano, R. (1989). Disability and depression in rheumatoid arthritis. A multitrait, multi-method investigation. Arthritis and Rheumatism, $32,1100-1106$

Pincus, T. and Callahan, L.F. (1993). Depression scores in rheumatoid arthritis: Criterion contamination of patient responses. Patient Education and Counseling, 20, 133-143.

Pincus, T., Callahan, L.F., Brooks, R.H., Fuchs, H.A., Olsen, N.J. and Kaye, J.J. (1989). Self-report questionnaire scores in rheumatoid arthritis compared with traditional physical, radiographic, and laboratory measures. Annals of Internal Medicine, 110, 259-266.

Rasker, J.J. and Cosh, J.A. (1987). The natural history of rheumatoid arthritis over 20 years. Clinical symptoms, radiological signs, treatment, mortality and prognostic significance of early features. Clinical Rheumatology, 6 (Suppl. 2), 5-11.

Ritchie, D.M., Boyle, J.A., McInnes, J.M., Jasani, M.K., Dalakos, T.G., Grieveson, P. and Buchanan, W.W. (1968). Clinical studies with an articular index for the assessment of joint tenderness in patients with rheumatoid arthritis. Quarterly Journal of Medicine, 37, 393-406.

Ruddy, S. (1985). The management of rheumatoid arthritis. In Kelley, W.N., Harris, E.D., Ruddy, S., Sledge, C.B. (Eds): Textbook of Rheumatology. Vol. 1, 2nd edition. Philadelphia, W.B. Saunders Comp.

Schumacher, H.R. (Ed). (1988). Primer on the Rheumatic Diseases, ninth edition, Atlanta GA: Arthritis Foundation.

Shoor, S.M. and Holman, H.R. (1984). Development of an instrument to explore psychological mediators of outcome in chronic arthritis. Transactions of the Association of American Physicians, 97, 325-331.

Sluijs, J.M. and Knibbe, J.J. (1991). Patient compliance with exercise: different theoretical approaches to short-term and long-term compliance. Patient Education and Counseling, 17, 191-204.

Taal, E., Jacobs, J.W., Seydel, E.R., Wiegman, O. and Rasker, J.J. (1989). Evaluation of the Dutch Arthritis Impact Measurement Scales (DUTCH-AIMS) in patients with rheumatoid arthritis. British Journal of Rheumatology, 28, 487-491.

Taal, E., Rasker, J.J., Seydel, E.R. and Wiegman, O. (1993). Health Status, adherence problems, self-efficacy and social support in patients with rheumatoid arthritis. Patient Education and Counseling, 20, 63-76. 
Taal, E., Seydel, E.R., Cliteur, H.M.E., Rasker, J.J., and Wiegman, O. (1991a). De problematiek van patiënten met reumatoide arthritis in de thuis-zorg: gesprekken met patiënten. [The problems of patients with rheumatoid arthritis in a home-care situation: interviews with patients]. Enschede, The Netherlands: University of Twente.

Taal, E., Seydel, E.R., Cliteur, H.M.E., Rasker, J.J., and Wiegman, O. (1991b). Voorlichting en begeleiding van patiënten met reumatoïde arthritis: Ervaringen van hulpverleners. [Patient education to patients with rheumatoid arthritis: experiences of health professionals]. Enschede, The Netherlands: University of Twente.

Taal, E., Seydel, E.R., Riemsma, R.P., Wiegman, O. and Rasker, J.J. (1991a). Omgaan met reumatoïde artritis: handleiding voor begeleiders van het groepsprogramma voor mensen met reumatoïde artritis. [Coping with rheumatoid arthritis: manual for groupleaders of the groupprogram for people with rheumatoid arthritis]. Enschede, The Netherlands: University of Twente.
Taal, E., Seydel, E.R., Riemsma, R.P., Wiegman, O. and Rasker, J.J. (1991b). Omgaan met reumatoide artritis: werkboek voor deelnemers aan het groepsprogramma voor mensen met reumatoïde artritis. [Coping with rheumatoid arthritis: workbook for participants in the groupprogram for people with rheumatoid arthritis]. Enschede, The Netherlands: University of Twente.

Taal, E., Seydel, E.R., Riemsma, R.P., Wiegman, O., and Rasker, J.J. (1991c). Omgaan met reumatoïde artritis: een zelf-hulpboek voor mensen met reumatoïde ariritis. [Coping with rheumatoid arthritis: a self-help guide for people with rheumatoid arthritis]. Enschede, The Netherlands: University of Twente.

Correspondence to: Erik Taal, MA, Department of Psychology, University of Twente, P.O.B. 217, 7500 AE Enschede, Netherlands. 